\title{
Active surveillance and focal ablation for small renal masses: a better solution for comorbid patients
}

\author{
Piotr Wośkowiak, Katarzyna Lewicka, Adrianna Bureta, Maciej Salagierski
}

The Faculty of Medicine and Health Sciences, University of Zielona Gora, Zielona Gora, Poland

Submitted: 6 June 2018

Accepted: 1 September 2018

Arch Med Sci 2020; 16 (5): 1111-1118

DOI: https://doi.org/10.5114/aoms.2019.86190

Copyright $\odot 2019$ Termedia \& Banach

\begin{abstract}
The natural history of small renal masses (SRM) is still not well understood and they are frequently incidentally diagnosed in elderly patients. Therefore, there is a need for less invasive options sparing the patient from the side-effects related to conventional surgical treatment. PubMed and Medline database search was performed to look for new findings on active surveillance and focal therapy for SRM. Sixty-one articles published between 2002 and 2018 were selected for the purpose of the review. There is growing evidence confirming the safety of active surveillance in patients at surgical risk and there appears to be a satisfactory intermediate-term outcome of focal treatment of SRM. In the group of elderly patients with a decreased life expectancy active surveillance appears to be the most appropriate approach. The future of minimally invasive therapy appears bright, especially with the improvement of new imaging modalities.
\end{abstract}

Key words: small renal mass, kidney, active surveillance, ablation, focal therapy.

\section{Introduction}

Each year nearly 200000 new cases of kidney tumors are diagnosed worldwide [1]. Due to the common use of abdominal ultrasonography (US), computed tomography (CT) and/or magnetic resonance imaging (MRI), most of the small renal masses (SRM, i.e., less than $4 \mathrm{~cm}$ ) are discovered incidentally in asymptomatic patients and at an early clinical stage. Stage T1 renal tumors (i.e., organ-confined and not exceeding $7 \mathrm{~cm}$ ) account for $>60 \%$ of cases. A lot of controversies remain regarding the management of SRM. At the end of the $20^{\text {th }}$ century, partial nephrectomy (PN) evolved from a rare procedure to the current standard of care, lessening the risk of chronic kidney disease and (possible) death by other causes in kidney cancer survivors. As shown in the literature, when the size and stage of kidney tumor development are low, there appears to be a very limited risk of metastasis and cancer-specific mortality [2]. As a consequence, over the last decade, alternative and much less invasive methods (i.e., ablative techniques) have been developed and evaluated. Due to the lack of adequate oncologic follow-up and several drawbacks, such as accuracy of pre- and postablation biopsy, the need for frequent imaging, and the high rate of benign pathology in SRM, ablative techniques are still being reserved for patients unfit for surgery. Importantly, in the group of elderly

\author{
Corresponding author: \\ Assoc. Prof. \\ Maciej Salagierski MD, PhD \\ Faculty of Medicine \\ and Health Sciences \\ Zyty 28 \\ 65-046 Zielona Gora, Poland \\ Phone: +48683283105 \\ E-mail: m.salagierski@wlnz. \\ uz.zgora.pl
}


patients, especially those with comorbidities and/ or who are at surgical risk, active surveillance (AS) becomes a preferable approach.

Finding an appropriate option of SRM management in poor surgical candidates is challenging. With the intention of making the right decision, one main problem needs to be debated - should it be an invasive or non-invasive way of management? Which one will bring better life expectancy, fewer complications and a better quality of life? There are lots of factors that need to be faced - most of all, the tumor size, patient's age and co-morbidities. Active surveillance is more advocated in elderly patients than radiofrequency ablation or cryoablation. However, the long-term effect of the ablations procedures is more stable and easier to predict compared to AS. This article will focus on describing the practical aspects of AS and the ablation techniques used in the management of SRM in surgically unfit patients.

\section{Material and methods}

We performed an English language literature search in PubMed/Medline in July 2018 using the following keywords: focal therapy, small renal masses, renal ablation, cryoablation, radiofrequency ablation, HIFU, microwave ablation, renal cell carcinoma (RCC). We looked through articles written in English between 2002 and 2018. Review articles, case reports, comments and editorials as well as congress abstracts were excluded. Studies that combined RCC outcomes with those of primary tumors other than RCC were excluded as well. Additional relevant articles were selected from manuscript bibliographies. Given the retrospective, mostly non-comparative design of the identified studies, the evidence synthesis was performed in a descriptive and narrative manner. For the purpose of the current review 61 articles published between 2002 and 2018 were selected.

\section{Results}

\section{Management of small renal masses}

\section{Active surveillance}

Active surveillance is one of the methods used more and more frequently in the management of SRM in elderly and/or high surgical risk patients. It appears to be a safer and more sensible approach than previously thought [3]. It is based on making a series of follow-up CT, MRI scans or other radiological imaging revealing any possible tumor progression [4]. The DISSRM protocol advises CT or MRI with contrast at the beginning, to be followed by CT or MRI every 4 to 6 months for 2 years and then every 6 to 12 months thereafter [5]. A high percentage of SRM are benign and can be safely managed with monitoring. Furthermore, SRM feature slow growth rates $(0.1-0.3 \mathrm{~cm}$ per year). This allows AS to be made available for this kind of lesions [6]. What is more, by selecting this option, several factors must be considered: tumor characteristics and location, risk of hemodialysis after intervention in the course of serious renal insufficiency, patient's age and negative attitude to this way of management, and mortality. Therefore, some patients with SRM may be safely observed but should be under close monitoring for tumor growth [7]. The role of a percutaneous needle biopsy appears also promising in the management of SRM. If the biopsy confirms the presence of a non-malignant lesion, surgical intervention or even a follow-up could be potentially avoided [8]. A common outcome is that the lesion is not a tumor at all. The surveillance approach is particularly designed for elders with multiple co-morbidities to avoid risk associated with surgical operations, such as partial nephrectomy [2]. Active surveillance is an option for these people and for those who choose not to have surgery because of fear or any other personal reasons. The age of 75 or over is accepted especially to consider AS owing to satisfactory life expectancy [9]. Among 445 elderly patients under the AS protocol, overall survival (OS) was $96 \%$ at 2 years, and $75 \%$ at 5 years, cancer-specific survival (CSS) $100 \%$ at 5 years [5]. Active surveillance is not recommended in young patients due to the low but real danger of expansion of a metastatic disease [2]. This group is rather treated with invasive procedures. Financial expenses are another advantageous aspect of AS. Radiological follow-up imaging generates significantly lower costs than even minimally invasive procedures. Nevertheless, as advised by Azawi et al., caution should be taken when offering AS. An analysis of the AS approach on 106 patients with SRM showed that metastases were discovered in $2.9 \%$ of examined patients even after surgical operations of masses smaller than $4 \mathrm{~cm}$. Therefore, AS must be limited to patients with a short life expectancy. Wider applicability of AS may be possible in the future. By choosing AS, all precautions should be taken, because even SRM could be aggressive [10].

\section{Ablative therapies}

Nephron-sparing surgery (NSS) is the gold standard in SRM management. However, in recent years we can observe a clear tendency towards focal destruction of cancer tissue, i.e. ablations or AS. That trend expresses the development and necessity of conservative treatment especially in patients at surgical risk. Several ablative techniques are commonly used nowadays when it comes to treatment of SRM. The most widely investigated and applied are cryoablation (CA) and radiofre- 
quency ablation (RFA). Methods such as microwave ablation (MWA), high-intensity focused ultrasound (HIFU), and irreversible electroporation (IRE) are being developed and evaluated. When compared to surgical therapy, minimally invasive ablative techniques present several advantages including reduction of pain and blood loss, which lead to a shorter hospital stay. Dynamic improvement of ablative techniques, development of new technologies and increasing experience of the operators give new treatment patterns to patients who are poor surgical candidates, especially with anatomically uncomplicated SRM. Furthermore, short hospitalization and cost-effectiveness of ablative therapies are promising in comparison to NSS, especially for the percutaneous approach [11, 12]. As far as oncological outcome is concerned, some studies show a benefit of NSS over ablative techniques and others give no evidence of significant difference between these two approaches considering metastatic disease, progression or local recurrence $[13,14]$. Each ablative therapy has its own advantages, which are described in detail below and summarized in Table I.

\section{Cryoablation}

The procedure is based on use of the cryoprobes depressurization argon or helium gas, giving typically two freeze-thaw cycles achieved by the Joule-Thomson effect [15]. A range of low temperatures from $-40^{\circ} \mathrm{C}$ to $-60^{\circ} \mathrm{C}$ (depending on tissue type) is required to achieve formation of ice crystals (known as iceballs) within cells, organelle damage, disruption of cell membrane, dehydration and consequently apoptosis, as well as the cell death cascade [16, 17]. Subsequent thawing results in cell edema and bursting due to the influx of extracellular fluid. Moreover, vascular thrombosis inducing local ischemia is the cause of impaired tissue repair $[15,18]$. Histologically, cryoablation results in occurrence of cholesterol crystals, dystrophic calcification and histiocyte influx (indicating coagulative necrosis) as well as hemorrhage within the margin of the ablation zone. Eventually fibrotic changes and scarring substitute the cryoablated lesion [19, 20]. Apart from the area of the mass the whole procedure takes into account a 5 to $10 \mathrm{~mm}$ margin constituting the ablation zone and is monitored in real time by thermocoupling or ultrasonography. Optimal results can be achieved by using multiple cryoprobes, which should be placed $1.5 \mathrm{~cm}$ apart and no more than $1 \mathrm{~cm}$ from the edge of the mass. The shape and size of the ablation zone can be customized by activation or deactivation of some cryoprobes during the procedure, giving the interventional radiologist the ability to actively monitor the ablation zone via US, CT or MRI due to iceball formation [21]. Moreover, the extent of the ablation zone is dependent on cryoprobe manufacturer or cryoprobe size [22]. In the case of cryoablation, two approaches are performed: percutaneous (PCA) and open/laparoscopic surgical (SCA) $[23,24]$. Selection of the method is primarily determined by location of the mass. Although the choice of the approach still seems to depend on the performing surgeon or institutional traditions, studies indicate that percutaneous cryoablation is

Table I. Comparison of non-invasive treatment options for small renal masses

\begin{tabular}{|c|c|c|}
\hline $\begin{array}{l}\text { Management of small } \\
\text { renal masses in patients } \\
\text { at surgical risk }\end{array}$ & Advantages & Disadvantages \\
\hline Active surveillance & $\begin{array}{l}\text { - Low cost } \\
\text { - Outpatient care possible } \\
\text { - Approved for elderly and frail } \\
\text { individuals }\end{array}$ & $\begin{array}{l}\text { - } \text { No long-term data } \\
\text { - Requires close follow-up } \\
\text { - } \text { Might put some patients at risk as no } \\
\text { local treatment given }\end{array}$ \\
\hline Cryoablation & $\begin{array}{l}\text { - Confirmed efficiency } \\
\text { - Well developed technically } \\
\text { - Presence of "ice ball" during procedure }\end{array}$ & - No long-term follow-up \\
\hline Radiofrequency ablation & $\begin{array}{l}\text { - Confirmed efficiency } \\
\text { - Well developed technically }\end{array}$ & $\begin{array}{l}\text { - No significant real-time changes during } \\
\text { procedure } \\
\text { - "Heat sink" effect } \\
\text { - No long-term follow-up }\end{array}$ \\
\hline Microwave ablation & $\begin{array}{l}\text { - Shorter time of procedure } \\
\text { - Minor procedural pain } \\
\text { - Ability to cover multiple SRM at once }\end{array}$ & $\begin{array}{l}\text { - There is not enough research confirming } \\
\text { efficiency }\end{array}$ \\
\hline $\begin{array}{l}\text { High-intensity focused } \\
\text { ultrasound }\end{array}$ & $\begin{array}{l}\text { - Extracorporeal approach which reduces } \\
\text { complications }\end{array}$ & $\begin{array}{l}\text { - Improvement is needed due to high } \\
\text { number of incomplete ablations }\end{array}$ \\
\hline $\begin{array}{l}\text { Irreversible } \\
\text { electroporation }\end{array}$ & $\begin{array}{l}\text { - No "heat sink" effect - suitable for } \\
\text { masses located near vessels and } \\
\text { collecting system }\end{array}$ & $\begin{array}{l}\text { - There is not enough research confirming } \\
\text { efficiency }\end{array}$ \\
\hline
\end{tabular}


associated with shorter hospital stay and lower hospital costs compared to the surgical approach. Technical success rate, major complication rate and mean follow-up time show no significant difference between percutaneous and laparoscopic cryoablation $[25,26]$.

\section{Radiofrequency ablation}

Radiofrequency ablation (RFA) uses alternating current of around $500 \mathrm{kHz}$ frequency, delivered through a probe to gain radiofrequency waves. It causes coagulative necrosis of target cells and surrounding margins with temperature $50-100^{\circ} \mathrm{C}$. There are a few systems controlling overheating of a needle, such as internal liquid cooling, pulsed delivery of energy, measuring impedance of a tissue or direct temperature of electrode in order to prevent vaporization and carbonization of the treated area [27]. Contrary to cryoablation, the operator cannot see any significant changes in mass appearance in real time during the procedure since heat energy distribution cannot be assessed on CT or US images. The percutaneous approach is used for treatment of posterior and lateral masses due to separation from intraperitoneal organs. For anteriorly located tumors laparoscopic RFA is generally required [28]. Radiofrequency ablation enables one to shorten hospitalization, and decreases complications and procedural costs [29]. Findings indicate that noncentral location and small size of masses raise the effectiveness of this method. Otherwise, for central tumors the "heat sink" effect can be observed due to spreading of energy brought in by the urinary tract system and local vessels [30].

\section{Microwave ablation}

The general principle, as in RFA, is to obtain a rise of a temperature in a specific location. However, it varies in the frequency of electrical current (0.9-2.5 $\mathrm{GHz}$ ), which belongs to the microwave spectrum [31]. Circulation of this current in a probe induces movements of water molecules in surrounding tissues so heat is produced and coagulative necrosis is observed [27]. The aim is to reach at least $60^{\circ} \mathrm{C}$ on target, measured by thermocouples [15]. In comparison to other ablation techniques MWA provides: higher temperatures if needed, covering larger and multiple volumes of SRM at once, shorter time of ablation and minor pain for a patient [32]. One of the studies revealed that 3-year survival of the patients after MWA (91.3\%) was similar to those after partial nephrectomy (96\%) [33].

\section{High-intensity focused ultrasound}

To achieve necrosis focused ultrasound waves are used. A heat of more than $65^{\circ} \mathrm{C}$ is obtained due to converting absorbed energy. Besides the noninvasive mechanism and sparing of surrounding tissues there are limitations, such as target depth, variability and movements. The exposure time and its intensity are crucial because of acoustic cavitation as a substitution for thermal necrosis. That leads to mechanical lysis and unpredictable changes caused by microbubbles' movement under high pressure [34]. Findings reveal that extracorporeal HIFU can result in incomplete ablation while the laparoscopic approach appears to be more effective; however, further studies are needed [35].

\section{Irreversible electroporation}

Irreversible electroporation is a non-thermal method using microsecond electrical pulses. The aim is to form nano-scale pores in membranes of ablated cells. This permeabilization leads to their death with minimal inflammation in surrounding tissue [36]. Moreover, connective tissue remains unchanged after the treatment and blood flow does not have an influence on energy given to $a b$ lated tissue. Therefore the 'heat sink' effect is not observed, which is promising for masses located close to blood vessels or the renal collecting system [37-39]. The latest findings showed that urothelium, 28 days after IRE, after temporary degeneration, starts to regenerate, whereas tumor cells and parenchyma are destroyed permanently [40].

\section{Ablation approach}

From all of the ablation methods described above only HIFU can be performed extracorporeally. Despite being the least invasive, effectiveness does not appear to reach a satisfactory level. Clinical efficacy differs in many studies, the rate of successful ablations usually being around $60 \%$ [34]. There is no cumulative dose effect so a repeat procedure is possible. Other techniques are performed by a percutaneous, laparoscopic or open approach. The latter will not be described in this review because open surgery is not desirable for mentioned patients with SRM, whereas laparoscopic technique is particularly useful for anterior tumors where there exists higher probability of damaging adjacent organs. Compared to laparoscopic NSS a lower complication rate is observed, but there is a higher probability of local recurrence $[3,41]$. Considering patient comorbidities and the general state of health which indicate that reducing the risk of procedural complications is essential, laparoscopic ablation is desirable for that group when the mentioned approach is needed.

Percutaneous ablations are suitable for posteriorly and laterally located masses, which can be 
accessed easily. Less invasive treatment and gradually better real-time imaging resulted in a predominantly performed percutaneous approach. For masses adjacent to the bowel hydrodissection provides a safe distance from a probe and overheating of surrounding structures by forming thermal insulation. It is especially indicated for patients with impaired renal function or a single kidney because of the slightly reduced nephrons number. Another advantage is quicker recovery with minor complications, which favorably affects the patients' comorbidities [42]. Short-term oncological outcomes are similar to partial nephrectomy, so if possible, percutaneous ablation should be performed [41, 43]. Summing up, if there is an indication to perform ablation in poor surgical candidates, location of a tumor is the most crucial aspect of the decision (Figure 1).

\section{Renal tumor biopsy}

The selection of optimal treatment also depends on tumor characteristics. Particularly in poor surgical candidates, knowledge of whether the mass is benign or malignant can lead to different management options. Also low-nuclear grading malignant tumor could be observed instead of not recommended surgical treatment for those patients. Therefore, the identification of benign lesion can be useful for assignment to active surveillance instead of intervention. However, most of the renal biopsies are performed at the time of ablation instead of the pre-treatment procedure. That excludes the ability to avoid unnecessary intervention, which is especially important for the mentioned patients. Associated risk of biopsy is below $1 \%$ of complications and results in minimal consequences; nonetheless, its usefulness is still discussed [44]. Patients with short life expectancy are not required to undergo biopsy because the further decision of AS will be independent of its result [45].

\section{Discussion}

Choosing the best treatment option for SRM is discussed due to the existence of a wide range of methods. Particularly in poor surgical candidates the choice is hindered due to the general state of their health. The decision about the intervention depends on many factors: age and life expectancy, comorbidities, impairment of renal function or presence of a solitary kidney, size, location and characteristics of a tumor or patient's wish. The current standard for management of SRM is partial nephrectomy; however, a higher complication rate and inevitability of general anaesthesia incline to a less invasive procedure for mentioned patients.

Patel et al. stated that in the short/intermediate term AS provides an alternative therapy to surgery. In comparison to partial and radical nephrectomy, overall and cancer-specific survival were not significantly different. Patients who underwent AS were older and the mean tumor size was smaller than those who were treated by surgery. $19.7 \%$ of a group managed with AS later received definitive treatment because of an increase in size of the mass, patient choice or alteration in radiological diagnosis [2]. That confirms the necessity of monitoring actual tumor progression and the utility of AS for patients with short life expectancy. Uzosike et al. observed, in a group of patients who were under AS, that no one died from kidney cancer or developed metastasis during the follow-up period. Growth rates of renal masses decreased with time of observation, which indicates a need for more frequent imaging especially at the beginning of AS [46]. Abouassaly et al. conducted an analysis of the treatment strategy for incidentally detected SRM on a wide range of patients. The age of 75 was the point when AS and/or ablative therapy appear to be a preferable and safe approach. Younger patients should be managed with initial active intervention, i.e. NSS. As the authors highlighted, results can vary from retrospective data by taking into consideration under-representation of patients in a poor state of health [9]. Jewett et al. investigated the mean tumor growth rate of 209 SRM in elderly patients. The average follow-up was 28 months and the increase in tumor diameter was $0.13 \mathrm{~cm} /$ year. Moreover, local pro-

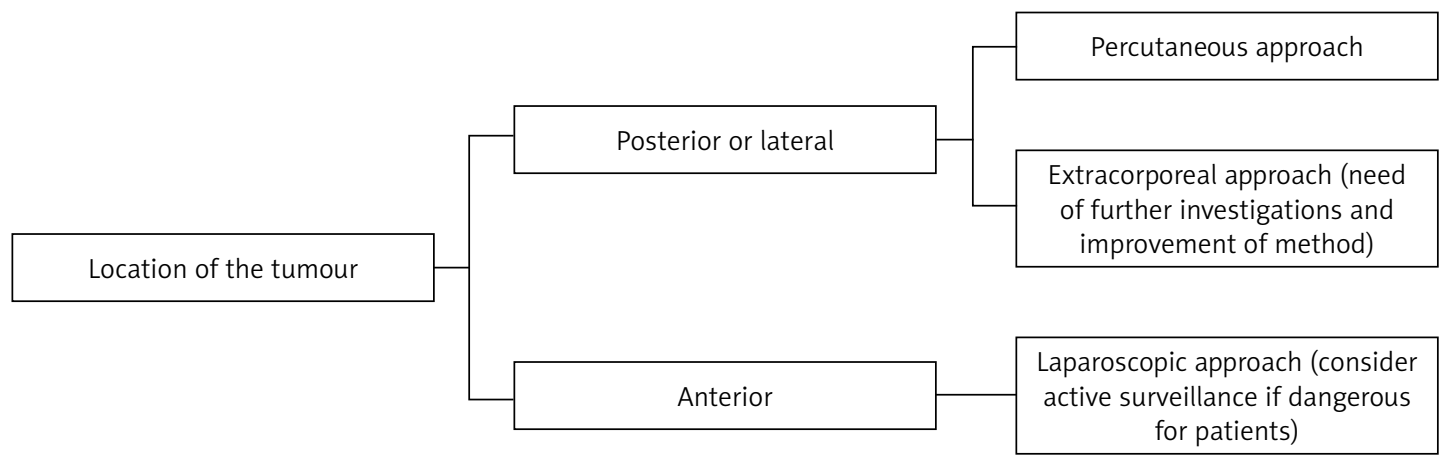

Figure 1. Choosing an ablation approach depending on the location of a tumour 
gression was observed in $12 \%$ and biopsy-proven presence of renal cell carcinoma did not substantially change the growth rate of masses. That indicates the utility of AS in infirm patients to avoid invasive treatment [47].

Psutka et al. presented long-term oncologic outcomes for RFA (median follow-up: 6.43 years). This study revealed that $92.3 \%$ of patients with T1a tumors were disease free and local recurrences occurred in only $4.2 \%$. If a T1b tumor was present outcomes respectively reached $76.2 \%$ and $14.3 \%$. That indicates the necessity of long-term observation in RFA patients, especially in higher stage tumors [48]. Zachos et al. reported that $90.6 \%$ of RFA under US guidance was primarily effective with no residual CT1a masses [49]. Wah et al. examined outcomes of RFA on 200 tumors [50]. Five percent of patients had major complications such as ureteric injury, abscess, acute tubular necrosis or calyceal-cutaneous fistula. Two percent developed significant renal function deterioration. Five-year OS was $75.8 \%$, CCS $97.9 \%$, local recurrence-free (LRFS) $93.5 \%$ and metastasis-free survival (MFS) 87.7\% [50]. Kunkle and Uzzo conducted a meta-analysis of SRM treatment by RFA and CA on a group of 1375 kidney lesions. Repeated ablation had to be performed in $8.5 \%$ of RFA and $1.3 \%$ of CA. Local tumor progression reached respectively $12.9 \%$ and $5.2 \%$, which suggest superiority of the second method. In the mentioned analysis 65\% of CA was laparoscopically performed and 94\% of RFA percutaneously, so outcomes could have varied from actual [51]. Particularly for elderly patients the crucial issue of fewer complications outweighs the laparoscopic ablation approach. However, in recent years there has been tendency to perform percutaneously also CA [41]. Atwell et al. compared CA and RFA in this approach. Outcomes were promising and similar for each method with inconsiderable superiority of RFA in local recurrence-free survival rates [52]. Importantly, there are many recent studies supporting the increasing role of both RFA and CA in the management of small renal masses [53-55].

Wah et al. reported that the efficacy of RFA can be predicted using dynamic contrast enhanced (DCE)-MRI. The perfusion of RCCs was examined in 21 patients who underwent RFA. The authors concluded that 1 month following ablation the perfusion significantly decreased in comparison

Table II. Clinical outcomes of SRM management

\begin{tabular}{|c|c|c|c|c|c|}
\hline Authors & $\begin{array}{l}\text { Manage- } \\
\text { ment }\end{array}$ & $\begin{array}{l}\text { Number of } \\
\text { tumors }\end{array}$ & $\begin{array}{l}\text { Tumor } \\
\text { diameter } \\
{[\mathrm{cm}]}\end{array}$ & $\begin{array}{l}\text { Median } \\
\text { follow-up } \\
\text { [months] }\end{array}$ & Results \\
\hline Patel et al. [2] & AS & 71 & 2.2 & 34 & $\begin{array}{l}\text { - Mean growth rate } 0.21 \mathrm{~cm} / \text { year } \\
\text { - OS } 83 \% \text {, CSS } 98.6 \% \text { - no significant } \\
\text { difference between PN and RN }\end{array}$ \\
\hline $\begin{array}{l}\text { Pierorazio } \\
\text { et al. [5] }\end{array}$ & AS & 223 & 1.9 & 25 & $\begin{array}{l}\text { - OS at } 2 \text { years } 96 \% \text {, at } 5 \text { years } 75 \% \text {, } \\
\text { - CSS at } 5 \text { years } 100 \%\end{array}$ \\
\hline $\begin{array}{l}\text { Jewett et al. } \\
{[47]}\end{array}$ & AS & 178 & 2.1 & 28 & $\begin{array}{l}\text { - Mean growth rate } 0.13 \mathrm{~cm} / \text { year } \\
\text { - Local progression in } 12 \% \text { and } 1.1 \% \text { with } \\
\text { metastases }\end{array}$ \\
\hline $\begin{array}{l}\text { Psutka et al. } \\
{[48]}\end{array}$ & RFA & 185 & 3.0 & 77 & $\begin{array}{l}\text { - Local recurrence } 6.5 \% \\
\text { - CSS at } 5 \text { years } 99.4 \% \\
\text { - Residual tumor in } 13 \% \\
\text { - T1b patients presented significantly worse } \\
\text { clinical outcome than T1a }\end{array}$ \\
\hline $\begin{array}{l}\text { Zachos et al. } \\
{[49]}\end{array}$ & RFA & 32 & 2.4 & 22 & $\begin{array}{l}\text { - Residual tumor in } 3 \% \\
\text { - Local recurrence in } 9.4 \%\end{array}$ \\
\hline $\begin{array}{l}\text { Wah et al. } \\
{[50]}\end{array}$ & RFA & 200 & 2.9 & 46.1 & $\begin{array}{l}\text { - 5-year OS, CSS, LRFS and MFS rates } \\
\text { of } 75.8 \%, 97.9 \%, 93.5 \% \text { and } 87.7 \% \\
\text { respectively }\end{array}$ \\
\hline $\begin{array}{l}\text { Kunkle and } \\
\text { Uzzo (meta- } \\
\text { analysis) [51] }\end{array}$ & $\begin{array}{l}\text { RFA and } \\
\text { CA }\end{array}$ & $\begin{array}{c}1375 \\
(775 \mathrm{RFA} \\
\text { and } 600 \mathrm{CA})\end{array}$ & 2.6 & 18.7 & $\begin{array}{l}\text { - Local recurrence in } 12.9 \% \text { RFA and } 5.2 \% \text { CA } \\
\text { - Residual tumor in } 8.5 \% \text { and } 1.3 \% \\
\text { respectively } \\
\text { - Progression to metastases in } 1.0 \% \text { and } \\
2.5 \% \text { respectively }\end{array}$ \\
\hline $\begin{array}{l}\text { Atwell et al. } \\
{[52]}\end{array}$ & $\begin{array}{l}\text { RFA and } \\
\text { CA }\end{array}$ & $\begin{array}{c}445 \\
(256 \text { RFA } \\
\text { and } 189 \mathrm{CA})\end{array}$ & $\begin{array}{l}1.9 \text { in RFA } \\
\text { and } 2.3 \text { in } \\
\quad C A\end{array}$ & $\begin{array}{l}33.6 \text { for } \\
\text { RFA and } \\
10.8 \text { for CA }\end{array}$ & $\begin{array}{l}\text { - Local recurrence in } 3.2 \% \text { RFA and } \\
\text { in } 2.8 \% \text { CA } \\
\text { - Major complications after } 4.3 \% \text { and } 4.5 \% \\
\text { respectively }\end{array}$ \\
\hline
\end{tabular}


to the pre-treatment measurement. Analyzing RCC blood flow enables early effects of RFA to be detected [56]. There is also a growing trend in using ultrasound contrast media not only to monitor the ablation procedures in real time but also in the follow-up imaging to screen for residual tumor [57].

Furthermore, ablative procedures can lead to post-ablation syndrome. Zhong et al. examined percutaneous CA and its influence on fever and flu-like symptoms. Only 6 of 64 patients (9\%) developed post-ablation syndrome and 33 (52\%) patients developed flu-like symptoms only [58].

Wu et al. treating advanced renal cell carcinoma with HIFU obtained reduction of pain and hematuria in all 10 patients with no sign of total ablation [59]. Then Marberger et al. reported that extracorporeal HIFU resulted in incomplete ablation of target tissue in all 18 cases [60]. Klingler et al. reported that in the laparoscopic approach all 31 patients who underwent this procedure using the new transducers demonstrated complete ablation [61]. Not only are multicenter studies on a larger group of patients treated with HIFU needed but also technical improvement of the method appears necessary. Similarly, MWA and IRE require further investigations. Current data do not allow them to be compared with other ablative methods and to definitely choose them. The clinical outcomes of SRM treatment by AS, RFA and CA are presented in Table II.

In conclusion, choosing the optimal treatment option in poor surgical candidates diagnosed with SRM requires consideration of the general condition of the patients, their life expectancy and comorbidities. Particularly when a patient does not agree to any intervention, may not survive it or the renal mass is around $2 \mathrm{~cm}$, AS should be offered. Follow-up observation provides information about the tumor growth rate so treatment can be altered depending on the situation. Only if the tumor diameter reaches a size of around $4 \mathrm{~cm}$ and there are no contraindications is percutaneous ablation recommended. Radiofrequency ablation or CA is advisable due to the confirmed intermediate-term oncological efficacy. Microwave ablation and IRE need further investigations in larger group of patients. However, MWA may replace in the future first-line techniques due to the shorter time of ablation and less procedural pain. Irreversible electroporation might become used for tumors located close to vessels or renal collecting system. The extracorporeal approach of HIFU is promising but technical improvement of the method is vital to reduce the number of incomplete ablations.

\section{Conflict of interest}

The authors declare no conflict of interest.

\section{References}

1. Dominguez-Escrig JL, Sahadevan K, Johnson P. Cryoablation for small renal masses. Adv Urol 2008; 2008: 1-10.

2. Patel N, Cranston D, Akhtar MZ, et al. Active surveillance of small renal masses offers short-term oncological efficacy equivalent to radical and partial nephrectomy. BJU Int 2012; 110: 1270-5.

3. Thomas AA, Campbell SC. Small renal masses: toward more rational treatment. Cleve Clin J Med 2011; 78: $539-47$.

4. Joji N, Challacombe B. Diagnosis and management of small renal masses: the new PSA? Trends Urol Men's Heal 2013; 33: 31-4.

5. Pierorazio PM, Johnson MH, Ball MW, et al. Five-year analysis of a multi-institutional prospective clinical trial of delayed intervention and surveillance for small renal masses: the DISSRM registry. Eur Urol 2015; 68: 408-15.

6. Almassi N, Gill BC, Rini B, Fareed K. Management of the small renal mass. Transl Androl Urol 2017; 6: 923-30.

7. American Cancer Society. Active Surveillance for Kidney Cancer. This topic last updated: August 1, 2017.

8. Kurban LA, Vosough A, Jacob P, et al. Pathological nature of renal tumors - does size matter? Urol Ann 2017; 9: 330-4.

9. Abouassaly R, Yang S, Finelli A, Kulkarni GS, Alibhai SMH. What is the best treatment strategy for incidentally detected small renal masses? A decision analysis. BJU Int 2011; 108: 223-31.

10. Azawi N, Lund L, Fode M. Renal cell carcinomas mass of $<4 \mathrm{~cm}$ are not always indolent. Urol Ann 2017; 9: 234-8.

11. Wang Y, Chen YW, Leow JJ, Levy AC, Chang SL, Gelpi FH. Cost-effectiveness of management options for small renal mass: a systematic review. Am J Clin Oncol 2016; 39: 484-90.

12. Aboumarzouk OM, Ismail M, Breen DJ, et al. Laparoscopic versus percutaneous cryotherapy for renal tumours: a systematic review and meta-analysis. J Endourol 2018; 32: 177-83.

13. Haber GP, Lee MC, Crouzet S, Kamoi K, Gill IS. Tumour in solitary kidney: laparoscopic partial nephrectomy vs laparoscopic cryoablation. BJU Int 2012; 109: 118-24.

14. O'Malley RL. A matched-cohort comparison of laparoscopic cryoablation and laparoscopic partial nephrectomy for treating renal masses. BJU Int 2007; 99: 395-8.

15. Ginzburg S, Tomaszewski JJ, Kutikov A. Focal ablation therapy for renal cancer in the era of active surveillance and minimally invasive partial nephrectomy. Nat Rev Urol 2017; 14: 669-82.

16. Gage AA, Baust J. Mechanisms of tissue injury in cryosurgery. Cryobiology 1998; 37: 171-86.

17. Hoffmann NE, Bischof JC. The cryobiology of cryosurgical injury. Urology 2002; 60: 40-9.

18. Levy D, Avallone A JJ. Current state of urological cryosurgery: prostate and kidney. BJU Int 2010; 105: 590-600.

19. Jang TL, Wang R, Kim SC, Troe T, Pins MR, Nadler RB. Histopathology of human renal tumors after laparoscopic renal cryosurgery. J Urol 2005; 173: 720-4.

20. Edmunds TB, Jr, Schulsinger DA, Durand DB, Waltzer WC. Acute histologic changes in human renal tumors after cryoablation. J Endourol 2000; 14: 139-43.

21. Gunn AJ, Gervais DA. Percutaneous ablation of the small renal mass - techniques and outcomes. Semin Interv Radiol 2014; 31: 33-41.

22. Rau AC, Siskey R, Ochoa JA, Good T. Factors affecting lethal isotherms during cryoablation procedures. Open Biomed Eng J 2016; 10: 62-71. 
23. Weight CJ, Fergany AF, Gunn PW, Lane BR. The impact of minimally invasive techniques on open partial nephrectomy: a 10-year single institutional experience. J Urol 2008; 180: 84-8.

24. Atwell TD, Farrell MA, Leibovich BC, et al. Percutaneous renal cryoablation: experience treating 115 tumors. J Urol 2008; 179: 2136-40.

25. Hinshaw JL, Shadid AM, Nakada SY, Hedican SP, Winter TC, Lee FT. Comparison of percutaneous and laparoscopic cryoablation for the treatment of solid renal masses. Am J Roentgenol 2008; 191: 1159-68.

26. Jiang K, Tang K, Guo X, et al. Laparoscopic cryoablation vs. percutaneous cryoablation for treatment of smal renal masses: a systematic review and meta-analysis. Oncotarget 2017; 8: 27635-44.

27. Khiatani MD, Dixon RG. Renal ablation update. Semin Interv Radiol 2014; 31: 157-66.

28. Kelly EF, Leveillee RJ. Image guided radiofrequency ablation for small renal masses. Int J Surg 2016; 36: 525-32.

29. Sterrett SP, Nakada SY, Wingo MS, Williams SK, Leveillee RJ. Renal thermal ablative therapy. Urol Clin North Am 2008; 35: 397-414.

30. Gervais DA, McGovern FJ, Arellano RS, McDougal WS, Mueller PR. Radiofrequency ablation of renal cell carcinoma: part 1, Indications, results, and role in patient management over a 6-year period and ablation of 100 tumors. AJR Am J Roentgenol 2005; 185: 64-71.

31. Breen DJ, Lencioni R. Image-guided ablation of primary liver and renal tumours. Nat Rev Clin Oncol 2015; 12 175-86.

32. Floridi C, De Bernardi I, Fontana F, et al. Microwave ablation of renal tumors: state of the art and development trends. Radiol Med 2014; 119: 533-40.

33. Hernández JI, Cepeda MF, Valdés F, Guerrero GD. Microwave ablation: state-of-the-art review. Onco Targets Ther 2015; 8: 1627-32.

34. Nabi G, Goodman C, Melzer A. High intensity focused ultrasound treatment of small renal masses: clinical effectiveness and technological advances. Indian J Urol 2010; 26: 331-7.

35. Kimura M, Baba S, Polascik TJ. Minimally invasive surgery using ablative modalities for the localized renal mass. Int J Urol 2010; 17: 215-27.

36. Tracy CR, Kabbani W, Cadeddu JA. Irreversible electroporation (IRE): a novel method for renal tissue ablation. BJU Int 2011; 107: 1982-7.

37. Rubinsky B, Onik G, Mikus P. Irreversible electroporation: a new ablation modality-clinical implications. Technol Cancer Res Treat 2007; 6: 37-48.

38. Scheffer HJ, Nielsen K, de Jong MC, et al. Irreversible electroporation for nonthermal tumor ablation in the clinical setting: a systematic review of safety and efficacy. J Vasc Interv Radiol 2014; 25: 997-1011.

39. Narayanan G, Doshi MH. Irreversible electroporation (IRE) in renal tumors. Curr Urol Rep 2016; 17: 15.

40. Wendler JJ, Pech M, Köllermann J, et al. Upper-urinary-tract effects after irreversible electroporation (IRE) of human localised renal-cell carcinoma (RCC) in the IRENE pilot phase 2 a ablate-and-resect study. Cardiovasc Intervent Radiol 2018; 41: 466-76.

41. Zondervan PJ, Buijs M, de la Rosette JJ, van Delden O, van Lienden K, Laguna MP. Cryoablation of small kidney tumors. Int J Surg 2016; 36: 533-40.

42. Regier M, Chun F. Thermal ablation of renal tumors: indications, techniques and results. Dtsch Arztebl Int 2015; 112: 412-8
43. Kasivisvanathan V, Raison N, Challacombe B. The diagnosis and management of small renal masses. Int J Surg 2016; 36: 493-4.

44. Leão RR, Richard PO, Jewett MA. The role of biopsy for small renal masses. Int J Surg 2016; 36: 513-7.

45. Campbell S, Uzzo RG, Allaf ME, et al. Renal mass and localized renal cancer: AUA guideline. J Urol 2017; 198: 520-9.

46. Uzosike AC, Patel HD, Alam R, et al. Growth kinetics of small renal masses on active surveillance: variability and results from the DISSRM registry. J Urol 2018; 199: 641-8.

47. Jewett MA, Mattar K, Basiuk J, et al. Active surveillance of small renal masses: progression patterns of early stage kidney cancer. Eur Urol 2011; 60: 39-44.

48. Psutka SP, Feldman AS, McDougal WS, McGovern FJ, Mueller P, Gervais DA. Long-term oncologic outcomes after radiofrequency ablation for $\mathrm{T} 1$ renal cell carcinoma. Eur Urol 2013; 63: 486-92.

49. Zachos I, Dimitropoulos K, Karatzas A, et al. Ultrasoundguided radiofrequency ablation for CT1a renal masses in poor surgical candidates: mid-term, single-center outcomes. Ther Adv Med Oncol 2016; 8: 331-8.

50. Wah TM, Irving HC, Gregory W, Cartledge J, Joyce AD, Selby PJ. Radiofrequency ablation (RFA) of renal cell carcinoma (RCC): experience in 200 tumours. BJU Int 2014; 113: 416-28.

51. Kunkle DA, Uzzo RG. Cryoablation or radiofrequency ablation of the small renal mass: a meta-analysis. Cancer 2008; 113: 2671-80

52. Atwell TD, Schmit GD, Boorjian SA, et al. Percutaneous ablation of renal masses measuring $3.0 \mathrm{~cm}$ and smaller: comparative local control and complications after radiofrequency ablation and cryoablation. AJR Am J Roentgenol 2013; 200: 461-6.

53. Azevedo AA, Rahal A Junior, Falsarella PM, et al. Image-guided percutaneous renal cryoablation: five years experience, results and follow-up. Eur J Radiol 2018; 100: 14-22.

54. Oselkin M, Cornish N, Homel P, Honig S, Silver D, Sobolevsky S. Safety and efficacy of cryoablation of renal tumors in a high-risk patient population at a community hospital. Arab J Intervent Radiol 2018; 2: 14-9.

55. Venyo AKG. Radiofrequency ablation of kidney tumours and lesions: a review of the literature. J Kidney Treat Diagn 2018; 1: 16-32.

56. Wah TM, Sourbron S, Wilson DJ, et al. Renal cell carcinoma perfusion before and after radiofrequency ablation measured with dynamic contrast enhanced MRI: A pilot study. Diagnostics (Basel) 2018; 8: pii: E3.

57. O'Neal D, Cohen T, Peterson C, Barr RG. Contrast-enhanced ultrasound-guided radiofrequency ablation of renal tumors. J Kidney Cancer VHL 2018; 5: 7-14.

58. Zhong J, Bambrook J, Bhambra B, et al. Incidence of post-ablation syndrome following image-guided percutaneous cryoablation of renal cell carcinoma: a prospective study. Cardiovasc Interv Radiol 2018; 41: 270-6.

59. Wu F, Wang ZB, Chen WZ, Bai J, Zhu H, Qiao TY. Preliminary experience using high intensity focused ultrasound for the treatment of patients with advanced stage renal malignancy. J Urol 2003; 170: 2237-40.

60. Marberger M, Schatzl G, Cranston D, Kennedy JE. Extracorporeal ablation of renal tumours with high-intensity focused ultrasound. BJU Int 2005; 95 Suppl 2: 52-5.

61. Klingler C, Margreiter M, Marberger M. New ablative treatments for small renal masses: HIFU ablation. Arch Esp Urol 2013; 66: 79-89. 